essential scientific facts with readable descriptions about the habits of each species, Dr Peterson's text is of interest both to the student and to the layman. Of the 122 species treated, 102 are native, nine introduced, ten domestic and one extinct (the sea mink).

By way of introduction the author includes several short essays on mammals and man, the class Mammalia, the origin and classification of mammals, the mammalian skeleton, and a key to the orders of mammals. Each species is illustrated in pen and ink drawings, followed by a short description, giving measurements, distribution, habitat and a review of the animal's biology. For many species the detailed distribution maps are the first available; the information on which they are based is often inadequate, but the author hopes that this will encourage others to fill in the gaps. For the specialist, adequate classified descriptions of the skull dimensions with superb skull drawings make this book of a standard equal to Hall and Kelson's The Mammals of North America (1959). For the conservationist, short notes describing the animal's status are included where applicable. The book makes a significant contribution to the existing knowledge of mammals, and is certainly well worth recommending.

PAUL JOSLIN

\title{
Nature's Paradise by Jen and Des Bartlett. Collins, 5 gns.
}

'Shoot and let live' - is the motto of more and more wildlife stalkers who confront animals not with high velocity rifles but with high powered lenses. Far from festooning some baronial hall like a bizarre Madame Tussauds, the new brand of animal stalkers like the Bartletts disport their kills in fine productions like this collection of several hundred photographs of Africa's wildlife. It is divided into eight ecological sections ranging from the Coral Reef to Snow on the Equator, and one deals with conservation projects, including Operation Noah financed by the FPS.

Predictably, that gaping hippo and yawning lion are included; the book would not be complete without an angry bull elephant charging out of the pages; and those zebra are still drinking from that waterhole framed by the magnificent Kilimanjaro. Despite these clichés, the quality of the photography is unrivalled and it is perhaps an invidious task to select any for particular praise. There are beautiful portraits of a mountain gorilla and a lesser flamingo, and a snarling cheetah sprawls across two pages with every hair in sharp detail. The collection is well balanced, with a liberal scattering of landscapes; views of hideously eroded countryside contrast with fertile scenes where enormous acacias cut black rhinoceroses down to size.

The impact of the photographs will sell this book and so it is all the more surprising that those given a double page spread are spoilt by the centre creases. Why no fold-outs? Despite this criticism, many will gain immense pleasure discovering Africa's animals through the Bartletts' viewfinder.

JOHN SPARKS

\section{Ecology of the Alpine Zone of Mount Kenya by M. J. Coe. Dr W. Junk. The Hague, 25 guilders.}

Dr Coe's eagerly awaited book will disappoint those who hoped for a broad treatment of the ecology of Mount Kenya, for it deals only with one zone, between $3,500-4,500 \mathrm{~m}$, below the glaciers and above the ericaceous (moorland) zone. These metric heights in themselves are suspiciously round to describe any ecological zone on a mountain so dissected and with much higher rainfall on eastern and southern than on northern and western slopes.

The alpine climate on these mountains is characterised by daily rather than 


\section{FPS GIFTS}
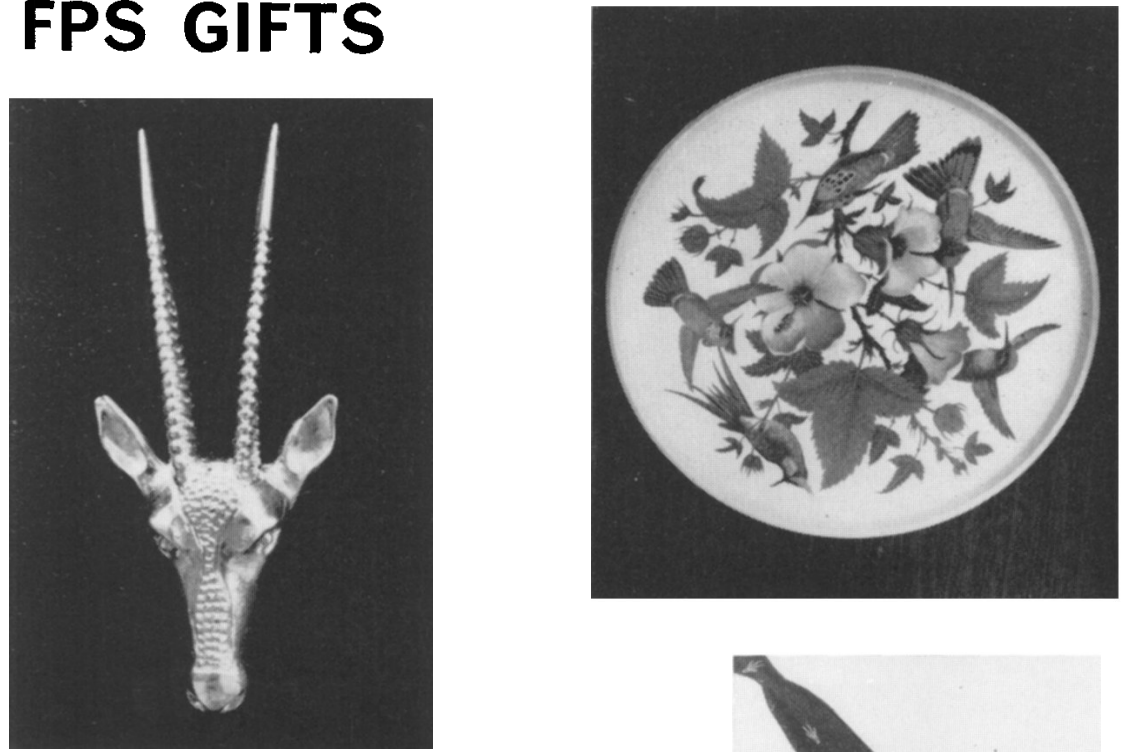

Oryx Brooch. The FPS emblem in sterling silver or $9 \mathrm{ct}$. gold, $1 \frac{1}{2} \mathrm{in}$. long, both hallmarked, and packed in velvet-lined box.

Chased silver: $£ 3$ 5s.; chased gold: $£ 8$;

plus 5s. packing and registered post (10s. air)

\section{Tray for Drinks top right.}

Decorative and practical Melamine trays, designed for the World Wildlife Fund, heat, stain and spirit proof, 12 in. diameter. Two full-colour designs: Humming Birds

(illustrated) and British Butterflies. 23s. each plus 3s. 6d. post and packing.

Matching Stands in the same design $6 \frac{1}{2}$ in. diameter, 10s. 6 d., plus 1 s. 9 d. post and packing.

Matching Set (tray and stand) either design, packed together, 32s. 6d. plus $4 \mathrm{~s}$. post and packing.

FPS Tie, Navy, green or maroon Terylene, $£ 1$ post free.

Scatter Dishes right. Six useful 4 in. Melamine dishes in a case each with a British wild mammal design (four illustrated). £1 1s. plus 2s. post and packing.
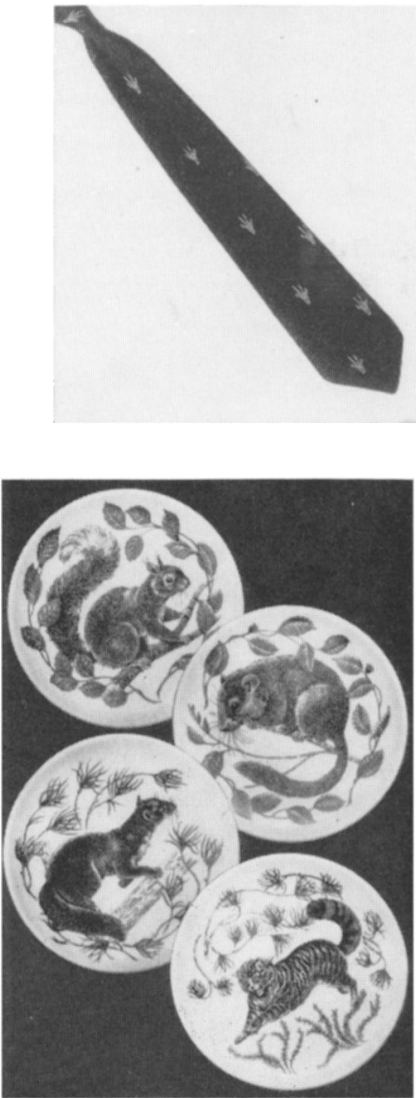


\section{Going to South Africa}

\section{... sea people have far more fun than jet people}

If you're in haste, fly. If you aren't, sail Union-

Castle and give yourself a wonderful time eleven days cruising through sunshine and blue sea with best food, best wine, best service, best everything. Experienced travellers sail with us over and over again.

If you must fly one way we have the perfect answer-inclusive holidays and travel using special air/sea arrangements. Ask your travel agent for further details. There are no currency restrictions in South Africa or on Union-Castle ships.

\section{UNION-CASTLE}

19 Old Bond Street, London, W.1. (01-493 8400) 
seasonal (winter/summer) variations such as occur in the Alps. The daily frostthaw alternation on equatorial heights results in rapid soil formation; plants and soil are daily subjected to temperature changes comparable to those that occur once a year on temperate mountains. Animals can avoid the nightly cold by burrowing or hiding among the leaf frills of giant groundsels, and even plants adapt to escape the worst effects of the climate. Plants that adopt the lowly rosette habit, also seen in the Arctic and the Alps, are more numerous than the giant (megaphytic) forms of groundsel or lobelia for which these heights are famous, and the rosette habit is shown to be a simpleadaptation to cold, abandoned as soon as the plant is taken to a warmer place. But no explanation is advanced for the occurrence of the bizarre and grotesque giant groundsels and lobelias.

The most interesting animal communities are the abundant rock hyrax and rats. Here the author draws some rather far-reaching conclusions about population control on what appears to be tenuous evidence. Birds are among the main predators of these animals and here the book is decidedly weak. It is suggested that the lammergeier Gypaëtus barbatus is resident and eats hyrax, but without a shred of real evidence.

The book is a mine of detailed information and a must for anyone interested in East African mountains. It is written by a specialist for specialists and a layman would find it unreadable, yet it is a book which many people may want to buy in the hope that it will reveal to them the natural secrets of Mt Kenya. If scientists wish to interest a wider public they should learn to write clearly and simply about their supremely interesting findings.

LESLIE BROWN

\section{The Past and Present Distribution of Some African Ungulates, by Jasmine Sidney. Transactions of the Zoological Society of London, Vol. $30, £ 6$.}

This fact-finding survey of certain elements of the African fauna - inspired and financed mainly by the Colonial Office and with assistance from the Department of Technical Co-operation - is based on data collected in the $1950 \mathrm{~s}$, during which time "there has been a pronounced acceleration in the decline in game numbers and game areas'; the situation has deteriorated still more in recent years. Miss Sidney summarises ten points to account for this decline, and stresses that 'only prompt action can save a valuable national resource from disappearing'; her advocacy of game-farming to provide protein for indigenous populations, as well as for perpetuating species, is both timely and practical. It is unfortunate that it has not been possible to include all African ungulates in this survey, which is, nevertheless, the most comprehensive and authoritative treatise ever to have been compiled on the subject. Many years of meticulous study and research are supplemented by two years' field experience in East, Central and Southern Africa, in 1958-59. The Continent is dealt with exhaustively, territory by territory; wholly or partially discussed, are six families, of which the extensive family Bovidae is divided into three sub-families, each of these further sub-divided into their relevant generic groups; the frequent distribution maps are particularly useful. The author is to be congratulated on this admirable treatise which constitutes a most valuable and informative work of reference.

C. R. S. PITMAN

\section{Poisonous Snakes of Southern Africa and the Treatment of Snakebite by John Visser. Howard Timmins, 45s.}

The primary purpose of this authoritative work, sponsored by the Cape of Good Hope Faculty of the College of General Practitioners, is the ready recognition of those Southern African poisonous snakes which endanger human life, combined with expert advice on the effects and treatment of snakebite. It is of such 